\title{
POTRET INDEKS KEPUASAN BIDAN TERHADAP PELAYANAN PUBLIK DI KABUPATEN BULELENG
}

\author{
Mandayani, Nyoman ${ }^{1}$, Darmini, Ketut Siya ${ }^{1}$, Purnawaman, I Gede ${ }^{1}$, Subanda, I \\ Nyoman ${ }^{1}$, Suarmini, Kadek $\mathrm{Ayu}^{2 *}$ \\ ${ }^{1}$ Program Studi Magister Administrasi Publik Undiknas Graduate School \\ ${ }^{2}$ Program Studi Profesi Kebidanan, Sekolah Tinggi Ilmu Kesehatan Buleleng \\ *Korespondensi: kadekayusuarmini@yahoo.co.id
}

\begin{abstract}
Backgroud: Public services perfomed by government officials in various sectors at this time are still found weaknesses. Weaknesses that occur when providing public services certainly have an impact on the quality of services received by the community. One of the public services performed by professional organizations is carried out by the branch manager of the Indonesian Midwives Association (IBI), Buleleng Regency. As for the form of public service provided is the management and extension of the midwife registration certificate (STRB) for the midwife. Purpose: The purpose of this study is to measure the midwife satisfaction index of public services conducted by the branch manager of the Indonesian midwives' branch of the Buleleng branch. Method: The research design used is descriptive research. The population in this study were all members of STRB. The sampling technique used is probability sampling technique with simple random sampling. Data collection techniques using a questionnaire with 14 closed questions. The questionnaire was distributed through WhatsApp IBI Buleleng group by providing a link for filling out the questionnaire on google form. Result: The results of this study of the 14 elements are almost entirely namely 13 elements that are in the good category and only one element that is in the category of not good enough category in the speed of service. Conclusion: Thus, it can be concluded that the portrait of the midwife satisfaction index of public services in the Buleleng Regency is in the good category, so it can be said that the quality of the services of the IBI PC on the Buleleng Regency is also in the good category.
\end{abstract}

Keywords: Administration; Midwife; Society Satisfaction Index; Public Services

ABSTRAK

Latar Belakang: Pelayanan publik yang dilakukan oleh aparatur pemerintah di berbagai sektor pada saat ini masih banyak dijumpai kelemahan. Kelemahan yang 
terjadi pada saat pemberian pelayanan publik tentu saja menimbulkan dampak pada kualitas pelayanan yang diterima oleh masyarakat. Salah satu pelayanan publik yang dilakukan oleh organisasi profesi dilakukan oleh Pengurus Cabang Ikatan Bidan Indonesia (IBI) Kabupaten Buleleng. Bentuk pelayanan publik yang diberikan adalah pengurusan dan perpanjangan Surat Tanda Registrasi Bidan (STRB) bagi bidan. Tujuan: Tujuan dari penelitian ini adalah untuk mengukur Indeks Kepuasan Bidan terhadap pelayanan publik yang dilakukan oleh Pengurus Cabang Ikatan Bidan Indonesia Cabang Buleleng. Metode: Desain penelitian yang digunakan adalah penelitian deskriptif.Populasi dalam penelitian ini adalah seluruh anggota IBI Kabupaten Buleleng yang pernah melakukan pengurusan dan perpanjangan STRB.Teknik sampling yang digunakan adalah teknik probability sampling dengan jenis simple random sampling. Teknik pengumpulan data menggunakan kuesioner dengan 14 pertanyaan tertutup. Kuesioner disebarkan melalui Whatsapp Group IBI Buleleng dengan memberikan link untuk pengisian kuesioner pada google form. Hasil: Hasil penelitian ini dari 14 unsur tersebut hampir seluruhnya yaitu 13 unsur berada pada kategori baik dan hanya satu unsur yang berada pada kategori kurang baik yaitu unsur kecepatan pelayanan. Simpulan: Dengan demikian maka dapat disimpulkan bahwa potret indeks kepuasan bidan terhadap pelayanan publik di kabupaten buleleng berada pada kategori baik, sehingga dapat dikatakan bahwa kualitas pelayanan di PC IBI Kabupaten Buleleng juga berada pada kategori baik.

Kata kunci : Administrasi; Bidan; Indeks Kepuasan Masyarakat; Pelayanan Publik

\section{PENDAHULUAN}

Pelayanan merupakan perwujudan fungsi pemerintahan dalam mengatur, mengendalikan, mengawasi, membina serta mengarahkan setiap aspek kehidupan masyarakat sehingga terwujud keseimbangan dalam pemberian pelayanan oleh aparatur pemerintah (Yudianto \& Harahap, 2010). Pelayanan publik berdasarkan atas tujuan, kewajiban, peran dan fungsi dalam upaya untuk memenuhi kebutuhan masyarakat terhadap barang dan jasa yang memiliki karakteristik sebagai barang publik (Kartikaningdyah, 2012).

Sebuah pelayanan yang maksimal merupakan upaya untuk mewujudkan kepuasan masyarakat sebagai pengguna layanan, kinerja pelayanan publik yang baik harus difokuskan pada pemenuhan kebutuhan masyarakat baik secara kualitas maupun kuantitas (Yudianto \& Harahap, 2010). Kepuasan pelanggan merupakan 
suatu alat ukur yang dapat digunakan agar dapat melihat dan merasakan baik tidaknya layanan yang diberikan (Putra, 2012).

Pelayanan publik yang dilakukan oleh aparatur pemerintah di berbagai sektor pada saat ini masih banyak dijumpai kelemahan. Suatu kelemahan yang terjadi pada saat pemberian pelayanan publik tentu saja menimbulkan dampak pada kualitas pelayanan yang diterima oleh masyarakat, hal ini dapat dilihat dari adanya penyampaian keluhan yang dilakukan oleh masyarakat baik melalui media massa maupun melalui forum (Athiyah, 2018).

Salah satu kegiatan yang dilakukan oleh sebuah organisasi adalah memberikan pelayanan baik kepada unit-unit kegiatan di dalam organisasi maupun kepada pihak diluar organisasi. Aktivitas pelayanan yang diberikan memiliki pengaruh terhadap pencapaian mutu dan kelancaran kegiatan organisasi seta berpengaruh terhadap pencapaian tujuan organisasi (Nugraheni, 2015). Dalam memberikan pelayanan yang baik, organisasi publik dituntut untuk dapat bertindak dengan cepat dan akurat. Pelayanan yang baik tercermin dari setiap efektivitas dan efisiensi kegiatan yang dilakukan dengan cepat dan akurat (Nugraheni, 2015).

Salah satu pelayanan publik yang dilakukan oleh organisasi profesi dilakukan oleh Pengurus Cabang Ikatan Bidan Indonesia (IBI) Kabupaten Buleleng. Adapun bentuk pelayanan publik yang diberikan adalah pengurusan dan perpanjangan Surat Tanda Registrasi Bidan (STRB) bagi bidan yang terdaftar sebagai anggota dari organisasi profesi IBI di kabupaten Buleleng.Kabupaten Buleleng memiliki 524 orang bidan, sehingga Buleleng menempati posisi kedua sebagai jumlah bidan terbanyak di Provinsi Bali setelahDenpasar.

Berdasarkan pengamatan awal yang dilakukan di kantor Pengurus Cabang IBI Kabupaten Buleleng, terdapat permasalahan yang masih sering dikeluhkan oleh sebagian anggota bidan adalah waktu pelayanan. Waktu untuk memproses pelayanan terkait pengurusan dan perpanjangan STRB sekitar dua minggu masih dianggap terlalu lama, walaupun dianggap lama layanan tersebut telah sesuai dengan ketentuan 
standard waktu pelayanan publik yang ditetapkan dalam undang-undang nomor 25 tahun 2009 tentang pelayanan publik.

Kegiatan pelayanan publik yang diberikan Pengurus Cabang IBI Kabupaten Buleleng, akan dinilai dari tingkat kepuasan masyarakat dalam hal ini bidan. Penilaian yang diberikan oleh masyarakat menentukan kinerja dari pelayanan publik adalah dengan mengukur tingkat kepuasan bidan.Salah satu metode yang digunakan untuk mengetahui kualitas pelayanan suatu organisasi publik adalah dengan menggunakan Indeks Kepuasan Masyarakat (IKM). Ketentuan mengenai Indeks Kepuasan Masyarakat (IKM) tertuang dalam Keputusan Menteri Pendayagunaan Aparatur Negara Nomor KEP/25/M.PAN/2/2004 tanggal 24 Februari 2004 tentang Pedoman Umum Penyusunan Indeks Kepuasan Masyarakat.

Analisis Indeks Kepuasan Masyarakat (IKM) harus selalu dilakukan secara berkala. Artinya pada setiap periode waktu tertentu harus dilakukan penelitian atau perhitungan dan analisis terhadap kepuasan bidan akan pelayanan yang telah diberikan. Akan tetapi sampai saat ini pengukuran atau analisis indeks Kepuasan Bidan belum pernah dilakukan di Pengurus Cabang IBI Kabupaten Buleleng.

Kepuasan bidan yang mempengaruhi kualitas pelayanan yang diberikan Pengurus Cabang IBI Kabupaten Buleleng menjadi hal yang menarik untuk diteliti, karena bermaksud untuk mengetahui lebih dalam mengenai Indeks Kepuasan Bidan terhadap pelayanan pengurusan dan perpanjangan STRB di kantor Pengurus Cabang IBI Kabupaten Buleleng.

Tujuan dari penelitian ini adalah untuk mengukur Indeks Kepuasan Bidan terhadap pelayanan publik yang dilakukan oleh Pengurus Cabang Ikatan Bidan Indonesia Cabang Buleleng.

\section{METODE}

Desain penelitian yang digunakan adalah penelitian deskriptif yang menghasilkan data berupa gambaran mengenai kepuasan bidan terhadap pelayanan 
Pengurus Cabang IBI Kabupaten Buleleng. Penelitian ini dilaksanakan di kantor Pengurus Cabang IBI Kabupaten Buleleng. Waktu pelaksanaan penelitian dilakukan pada bulan November hingga bulan Desember 2019. Populasi dalam penelitian ini adalah seluruh anggota IBI Kabupaten Buleleng yang pernah melakukan pengurusan dan perpanjangan STRB. Teknik sampling yang digunakan adalah teknik probability sampling dengan jenis simple random sampling. Besarnya responden yang digunakan sebagai sampel dalam penelitian ini adalah 150 orang bidan.

Teknik pengumpulan data menggunakan kuesioner dengan 14 pertanyaan tertutup, mengenai : prosedur pelayanan, persyaratan pelayanan, kejelasan petugas pelayanan, kedisiplinan petugas pelayanan, tanggung jawab petugas pelayanan, kecepatan pelayanan, keadilan mendapatkan pelayanan, kesopanan dan keramahan petugas, kewajaran biaya pelayanan, kepastian biaya pelayanan, kepastian jadwal pelayanan, kenyamanan lingkungan, dan keamanan pelayanan. Instrument penelitian ini menggunakan skala ukur bertingkat dengan jawaban : SS=Sangat Setuju memiliki skala 4, S=Setuju memiliki skala 3, TS=Tidak Setuju memiliki skala 2, dan STS=Sangat Tidak Setuju memiliki skala 1. Telah dilakukan uji coba instrument penelitian dengan menguji validitas dan reliabilitas. Uji validitas menggunakan Product Moment Pearson Correlationdengan hasil 14 pertanyaan valid dan Uji Reliabilitas menggunakan Cronbach's Alpha dengan hasil reliable dengan koefisien Cronbach's Alpha 0,754 lebih besar dari 0,349. Kuesioner disebarkan melalui Whatsapp Group IBI Buleleng dengan memberikan link untuk pengisian kuesioner pada google form.

Teknik analisis data pada penelitian ini menggunakan teknik analisis data IKM sesuai dengan KEPMENPAN Nomor 25 Tahun 2004. Teknik analisis data dilakukan dengan menggunakan nilai INDeks Kepuasan Masyarakat (IKM) yang dihitung dengan menggunakan nilai rata-rata tertimbang masing-masing unsur pelayanan. Setiap unsur pelayanan mempunyai penimbang yang sama dengan rumus sebagai berukut : 
Bobot nilai rata-tara tertimbang $\underset{\text { jumlahunsur }}{\text { jumlahbobot }}=\frac{1}{14}=0,071$

Untuk memperoleh nilai Indeks Kepuasan Masyarakat (IKM) digunakan rumus sebagai berikut:

$$
\text { IKM }=\frac{\text { Total dari Nilai Persepsi Per Unsur }}{\text { Total unsur yang terisi }} \times \text { Nilai Penimbang }
$$

Untuk mempermudah interpretasi nilai IKM yang berkisar 25-100, sesuai dengan ketentuan KEPMENPAN Nomor 25 Tahun 2004, maka hasil penilaian tersebut diatas dikonversikan dengan nilai dasar 25 , menggunakan rumus:

\section{NilaiKonversi IKM = NilaiIKM Unit Pelayanan x 25}

Hasil perhitungan tersebut kemudian dikategorikan sesuai dengan nilai persepsi dan interval nilai IKM seperti table berikut :

\begin{tabular}{|c|c|c|c|c|}
\hline $\begin{array}{c}\text { Nilai } \\
\text { Persepsi }\end{array}$ & $\begin{array}{c}\text { Nilai Interval } \\
\text { IKM }\end{array}$ & $\begin{array}{c}\text { Nilai Interval } \\
\text { Konversi IKM }\end{array}$ & $\begin{array}{c}\text { Mutu } \\
\text { Pelayanan }\end{array}$ & $\begin{array}{c}\text { Kinerja } \\
\text { Unit } \\
\text { Pelayanan }\end{array}$ \\
\hline 1 & $1,00-1,75$ & $25-43,75$ & D & Tidak baik \\
\hline 2 & $1,76-2,50$ & $43,76-62,50$ & $\mathrm{C}$ & Kurang baik \\
\hline 3 & $2,51-3,25$ & $62,51-81,25$ & $\mathrm{~B}$ & Baik \\
\hline 4 & $3,26-4,00$ & $81,26-100,00$ & $\mathrm{~A}$ & Sangat baik \\
\hline
\end{tabular}

(KEPMENPAN NomorKEP/25/M.PAN/2/2004)

Untuk mendapatkan nilai rata-rata tertimbang per unsur pelayanan jumlah nilai rata-rata per unsur pelayanan dikalikan dengan 0,071 sebagi nilai bobot rata-rata tertimbang.Hasil tersebut merupakan nilai dari Indeks Kepuasan Bidan terhadap pelayanan publik di Kabupaten Buleleng. 


\section{HASIL}

Melalui kuesioner berupa google form yang dikirimkan melalui Whatsapp Group dengan jumlah 14 pertanyaan tertutup. Responden adalah 150 orang bidan yang pernah mengurus dan memperpanjang STRB. Indeks Kepuasan Masyarakat digunakan untuk mengetahui bagaimana tanggapan bidan pengguna layanan terhadap layanan yang telah diberikan kepadanya. Indeks ini digunakan sebagai tolok ukur dari kualitas pelayanan Pengurus Cabang IBI Kabupaten Buleleng yang digambarkan kedalam dua bahasan, yang pertama mengenai karakteristik responden dan yang kedua mengenai analisis indeks kepuasan bidan.

\section{Karakteristik Responden}

Dari kuesioner yang diberikan kepada 150 orang responden, yaitu bidan yang telah melakukan pengurusan dan perpanjangan STRB di Kabupaten Buleleng, terdapat karakteristik masing-masing responden berdasarkan umur dan tingkat pendidikan.

Tabel 1 Distribusi Frekuensi Umur dan Tingkat Pendidikan

\begin{tabular}{ccc}
\hline Karakteristik & Jumlah (n) & Persentase (\%) \\
\hline Umur (Tahun) & 34 & 22,67 \\
$17-25$ & 47 & 31,33 \\
$26-35$ & 39 & 26 \\
$36-45$ & 30 & 20 \\
$46-55$ & 3 & 2 \\
Pendidikan & 106 & 70,67 \\
< D III & 36 & 24 \\
D III & 5 & 3,33 \\
D IV/S1 & & \\
S2 & &
\end{tabular}

Sumber: data primer

Berdasarkan tabel 1 diatas dapat dilihat bahwa dari 150 orang responden, paling banyak berada pada rentang usia 26-35 tahun yaitu sebanyak 47 orang $(31,33 \%)$ responden. Mayoritas responden berada pada tingkat pendidikan D3 yaitu sebanyak 106 orang $(70,67 \%)$ responden. 


\section{Analisis Indeks Kepuasan Bidan}

Kepuasan bidan dapat diketahui dengan melihat kualitas pelayanan dari 14 unsur yang telah ditentukan, adapun unsur kepuasan bidan adalah sebagai berikut:

Tabel 2 Nilai Rata-Rata Dari Masing-Masing Unsur Indeks Kepuasan Bidan

\begin{tabular}{clccc}
\hline No & \multicolumn{1}{c}{ Unsur Pelayanan } & $\begin{array}{c}\text { Bobot Rata- } \\
\text { Rata Unsur }\end{array}$ & $\begin{array}{c}\text { Nilai Rata-Rata } \\
\text { Unsur }\end{array}$ & Keterangan \\
\hline 1 & Prosedur Pelayanan & 448 & 2,98 & Baik \\
2 & Persyaratan Pelayanan & 428 & 2,85 & Baik \\
3 & Kejelasan Petugas Pelayanan & 446 & 2,97 & Baik \\
4 & Kedisiplinan Petugas & 410 & 2,73 & Baik \\
& Pelayanan & & & \\
5 & Tanggung Jawab Petugas & 443 & 2,95 & Baik \\
& Pelayanan & & & \\
6 & Kemampuan Petugas & 417 & 2,78 & Baik \\
& Pelayanan & 457 & 2,38 & Kurang Baik \\
7 & Kecepatan Pelayanan & 439 & 2,92 & Baik \\
8 & Keadilan Petugas Pelayanan & 454 & 3,02 & Baik \\
9 & Kesopanan Dan Keramahan & 412 & 2,74 & Baik \\
& Petugas & 414 & 2,76 & Baik \\
10 & Kewajaran Biaya Pelayanan & 428 & 2,85 & Baik \\
11 & Kepastian Biaya Pelayanan & 452 & 3,01 & Baik \\
12 & Kepastian Jadwal Pelayanan & 453 & 3,02 & Baik \\
13 & Kenyamanan Lingkungan & $\mathbf{6 0 0 1}$ & $\mathbf{3 9 , 9 6}$ & Baik \\
14 & Keamanan Lingkungan & Jumlah & &
\end{tabular}

Sumber: data primer

Dari tabel 2 diatas, nilai rata-rata dari masing-masing unsur indeks kepuasan bidan dapat dilihat hasil 14 unsur yang diteliti pada penelitian ini. Dari 14 unsur tersebut hampir seluruhnya yaitu 13 unsur berada pada kategori baik dan hanya satu unsur yang berda pada kategori kurang baik. 


\section{PEMBAHASAN}

Prosedur pelayanan yaitu kemudahan tahapan pelayanan yang diberikan kepada masyarakat dilihat dari sisi kesederhanaan alur pelayanan (Fardhani, 2010). Penilaian kinerja atas prosedur pelayanan yang berada pada kategori baik mengindikasikan bahwa kondisi pelayanan yang berhubungan dengan prosedur pelayanan yang baik dikarenakan adanya pengumuman atau informasi yang mudah diakses oleh masyarakat pengguna layanan.

Persyaratan pelayanan yaitu, persyaratan teknis dan administratif yang diperlukan untuk mendapatkan pelayanan sesuai dengan jenis pelayanan (Kamarni, 2011). Penilaian persyaratan pelayanan yang mendapatkan nilai baik mengindikasikan bahwa kesesuaian antara tingkat kemudahan persyaratan pelayanan baik mengenai tingkat keterbukaan dan kejelasan persyaratan.

Kejelasan petugas pelayanan yaitu keberadaan dan kepastian mengenai petugas yang memberikan pelayanan (Sukamti \& Utomo, 2015). Penilaian kejelasan petugas pelayanan yang mendapatkan nilai baik mengindikasikan bahwa kejelasan mengenai keberadaan petugas pelayanan dan kejelasan identitas serta tanggung jawab di PC IBI Kabupaten Buleleng baik.

Kedisiplinan petugas pelayanan merupakan kesungguhan petugas dalam memberikan pe;ayanan terutama terhadap konsistensi waktu kerja sesuai dengan ketentuan yang berlaku (Putra, 2012). Penilaian kinerja tentang kedisiplinan petugas pelayanan yang mendapatkan nilai baik mengindikasikan bahwa petugas pelayanan di PC IBI Kabupaten Buleleng mengenai tingkat ketepatan dalam melayani pasien sudah disiplin.

Tanggung jawab petugas pelayanan merupakan kejelasan wewenang dan tanggung jawab dalam penyelenggaraan dan penyelesaian pelayanan (Putra, 2012). Penilaian kinerja atas tanggung jawab petugas pelayanan yang mendapatkan nilai baik mengindikasikan bahwa tanggung jawab petugas pelayanan akan fungsi dan tugas masing-masing sudah dilaksanakan denganbaik. 
Kemampuan petugas pelayanan adalah tingkat keahlian dan keterampilan yang dimiliki petugas dalam memberikan atau menyelesaikan pelayanan kepada pengguna jasa (Yudianto \& Harahap, 2010). Penilaian kemampuan petugas dalam memberikan pelayanan yang mendapatkan nilai baik mengindikasikan bahwa bidan berpendapat jika kemampuan intelektual petugas PC IBI Kabupaten Buleleng sudah tidak diragukan lagi karena SDM yang ada merupakan orang yang ahli dan berkompeten dalam bidangnya dan juga memiliki pengalaman.

Keadilan dalam mendapatkan pelayanan merupakan pelaksanaan pelayanan dengan tidak membedakan golongan masyarakat yang dilayani (Putra, 2012). Penilaian keadilan mendapatkan pelayanan mendapatkan nilai pada kategori baik, bidan berpendapat jika mereka mendapatkan kesamaan perlakuan dan kemerataan dalam mendapatkan pelayanan tanpa membedakan status maupun latar belakang ekonomi.

Kesopanan dan keramahan petugas yaitu sikap dan perilaku petugas dalam memberikan pelayanan kepada masyarakat secara sopan dan ramah serta saling menghargai dan menghormati (Dahmiri, 2014). Penilaian kesopanan dan keramahan petugas pelayanan mandapatkan nilai yang baik mengindikasikan bahwa bidan berpendapat jika petugas di PC IBI Kabupaten Buleleng dalam memberikan pelayanan disertai sikap yang sopan dan ramah terhadap bidan yang dating untuk mengurus keperluan STRB.

Kewajaran biaya pelayanan adalah keterjangkauan masyarakat terhadap biaya yang telah ditetapkan oleh unit pelayanan (Nurrizka \& Saputra, 2011). Penilaian kewajaran biaya pelayanan yang mendapatkan nilai baik mengindikasikan bahwa bidan yang mengurus STRB berpendapat jika biaya yang mereka keluarkan wajar sesuai dengan jenis pelayanan yang diberikan.

Kepastian biaya pelayanan yaitu kesesuaian antara biaya yang dibayarkan dengan biaya yang ditetapkan (Ningtyas, Widowati, \& Maesaroh, 2013). Penilaian kepastian biaya pelayanan yang mendapatkan nilai baik mengindikasikan bahwa 
bidan memiliki pendapat jika kejelasan dan keterbukaan mengenai rincian biaya sudah dilaksanakan dengan baik.

Kepastian jadwal pelayanan adalah pelaksanaan waktu pelayanan yang sesuai dengan ketentuan yang telah ditetapkan (Hariany \& Matondang, 2014). Kinerja mengenai kepastian jadwal pelayanan yang mendapatkan nilai baik mengindikasikan bahwa sebagian besar bidan berpendapat jika kepastian jadwal pelayanan dapat dihandalkan dan dapat dipertanggung jawabkan.

Kenyamanan lingkungan yaitu kondisi sarana dan prasarana pelayanan yang bersih, rapi dan teratur sehingga dapat memberikan rasa nyaman kepada penerima pelayanan (Hernikawati, 2018). Penilaian tentang kenyamanan lingkungan yang mendapatkan nilai baik mengindikasikan bahwa bidan menyatakan jika kenyamanan lingkungan di PC IBI Kabupaten Buleleng yang terdiri dari kebersihan lingkungan, ketersediaan fasilitas pendukung serta kelengkapan sarana dan prasarana berada dalam kondisi baik.

Keamanan pelayanan yaitu terjaminnya tingkat keamanan lingkungan unit penyelenggara pelayanan ataupun sarana yang digunakan, sehingga masyarakat merasa tenang untuk mendapatkan pelayanan (Athiyah, 2018). Penilaian tentang keamanan lingkungan berada pada kategori baik, mengindikasikan bahwa responden menyatakan jika keamanan lingkungan di PC IBI Kabupaten Buleleng baik didalam ruangan pelayanan maupun diluar ruangan sudah aman.

Adapun unsur yang berada pada kategori kurang baik adalah kecepatan pelayanan. Kecepatan pelayanan yaitu target waktu pelayanan dapat diselesaikan dalam waktu yang telah ditentukan oleh unit penyelenggara pelayanan (Dahmiri, 2014). Penilaian kinerja kecepatan pelayanan yang mendapatkan nilai kurang baik mengindikasikan bahwa bidan di kabupaten buleleng berpendapat jika PC IBI Kabupaten Buleleng belum menerapkan standar waktu pelayanan. Berdasarkan data nilai rata-rata unsur maka nilai indeks secara keseluruhan adalah 71 , maka mutu 
pelayanan PC IBI Kabupaten Buleleng berada pada kategori B dan kinerja unit pelayanan dengan kategori Baik.

\section{SIMPULAN DAN SARAN}

Nilai rata-rata dari masing-masing unsur indeks kepuasan bidan dapat dilihat hasil 14 unsur yang diteliti pada penelitian ini. Dari 14 unsur tersebut hamper seluruhnya yaitu 13 unsur berada pada kategori baik dan hanya satu unsur yang berada pada kategori kurang baik.Adapun unsur yang berada pada kategori kurang baik adalah kecepatan pelayanan.Penilaian kinerja kecepatan pelayanan yang mendapatkan nilai kurang baik mengindikasikan bahwa bidan di kabupaten buleleng berpendapat jika PC IBI Kabupaten Buleleng belum menerapkan standar waktu pelayanan.

Dengan demikian nilai indeks unit pelayanan dapat disimpulkan sebagai berikut : Nilai IKM setelah dikonversi $=$ Nilai indeks x Nilai penimbang $=2,84 \times 25$ =71, maka mutu pelayanan PC IBI Kabupaten Buleleng berada pada kategori B, dan kinerja unit pelayanan dengan kategori Baik. Dapat disimpulkan bahwa potret indeks kepuasan bidan terhadap pelayanan publik di kabupaten buleleng berada pada kategori baik, sehingga dapat dikatakan bahwa kualitas pelayanan di PC IBI Kabupaten Buleleng juga berada pada kategori baik.

Rekomendasi untuk penelitian selanjutnya adalah kedepannya proses pelayanan ditingkatkan kembali baik dalam hal pelayanan perpanjangan STR, surat praktik dan hal lainnya. Walaupun dalam hal ini indeks kepuasan sudah baik namun untuk kedepannya pelayanan akan terus diperbaiki agar indeks kepuasan juga semakin meningkat.

\section{DAFTAR PUSTAKA}

Athiyah, C. U. (2018). Pengukuran Indeks Kepuasan Peserta Diklat TOT Widyaiswara di Pusdiklat Tenaga Teknis Pendidikan dan Keagamaan Tahun 2018. Andragogi: Jurnal Diklat Teknis Pendidikan Dan Keagamaan, 6, 70-84. 
Dahmiri. (2014). Analisa Kepuasan Masyarakat terhadap Kinerja Pelayanan Kantor Camat Kecamatan Sarolangun. Jurnal Studi Manajemen, 8, 132-144.

Fardhani, H. (2010). Analisis Faktor-Faktor Yang Mempengaruhi Kepuasan Masyarakat Pada Pelayanan Badan Pelayanan Perijinan Terpadu Kota Semarang. Semarang.

Hariany, Z., \& Matondang, R. (2014). Analisis Indeks Kepuasan Masyarakat (IKM) Terhadap Pelayanan Publik Di Puskesmas XXX. Jurnal Teknik Industri USU, 5, 17-21.

Hernikawati, D. (2018). Indeks Kepuasan Masyarakat Terhadap Pelayanan Komunikasi Data di PJKKD Batan. Jurnal Studi Komunikasi Dan Media, 22, 29-43.

Kamarni, N. (2011). Analisis Pelayanan Publik Terhadap Masyarakat (Kasus pelayanan Kesehatan di Kabupaten Agam). Jurnal Manajemen Dan Kewirausahaan, 2, 84-117.

Kartikaningdyah, E. (2012). Analisis Indeks Kepuasan Masyarakat Terhadap Pelayanan Publik Pada BP2T Kota Tanjungpinang. Jurnal Integrasi, 4, 136-147.

Ningtyas, R., Widowati, N., \& Maesaroh, M. (2013). Analisis Indeks Kepuasan Masyarakat (IKM) Terhadap Kualitas Pelayanan di Puskesmas Bandarharjo di Kecamatan Semarang Utara. Semarang: Universitas Diponogoro.

Nugraheni, Z. A. A. (2015). Analisis Kepuasan Masyarakat Terhadap Pelayanan Publik Berdasarkan Indeks Kepuasan Masyarakat di Kantor Kecamatan Mungkid Kabupaten Magelang. https://doi.org/10.1590/s1809-98232013000400007

Nurrizka, R. H., \& Saputra, W. (2011). Pengukuran Indeks Kepuasan Masyarakat Terhadap Pelayanan Kesehatan. Jurnal Manajemen Pelayanan Kesehatan, 14, 11-19.

Putra, Y. S. (2012). Analisis Indeks Kepuasan Masyarakat (IKM) Terhadap Pelayanan Publik di Puskesmas Tegalrejo Kota Salatiga Tahun 2012. Jurnal Among Makarti, 5, 14-41.

Sukamti, S., \& Utomo, H. (2015). Analisis Indeks Kepuasan Masyarakat (IKM) Pada Pelayanan Publik Di Puskesmas Kalicacing Kota Salatiga. Jurnal Ilmiah Among Makarti, 8, 1-15.

Yudianto, B., \& Harahap, R. H. (2010). Analisis Indeks Kepuasan Masyarakat Terhadap Kinerja Pelayanan Lelang Pada Kantor Pelayanan Kekayaan Negara dan Lelang (KPKNL) Medan. Administraso Publik, 6, 1-30. 